\title{
Trust and prosocial behaviour in a process of state capacity building: the case of the Palestinian territories ${ }^{1}$
}

\author{
LUCA ANDRIANI* \\ Department of Management, Birkbeck University of London, London, United Kingdom \\ FABIO SABATINI** \\ Department of Economics and Law, Sapienza University of Rome, Italy and Laboratory for Comparative Social \\ Research, National Research University Higher School of Economics, Russia (grant \# 11.G34.31.0024 from November \\ $28,2010)$
}

\begin{abstract}
This paper contributes to the literature by conducting the first empirical investigation into the determinants of prosocial behaviour in the Palestinian Territories, with a focus on the role of trust and institutions. Drawing on a unique dataset collected through the administration of a questionnaire to a representative sample of the population of the West Bank and the Gaza Strip, we have found that institutional trust is the strongest predictor of prosociality. This result suggests that, in collectivist societies with low levels of generalized trust, the lack of citizens' confidence in the fairness and efficiency of public institutions may compromise social order. The strengthening of institutional trust may also reinforce prosocial behaviour in individualist societies, where a decline in generalized trust has been documented by empirical studies.
\end{abstract}

\section{Introduction}

Prosocial individuals 'tend to be natural co-operators. They will strive to maximize joint outcomes and equality in outcomes, or sometimes even other outcomes (altruism) and they seek win-win situations to disagreement' (Bogaert

\footnotetext{
*Email: luca.andriani@bbk.ac.uk

**Email: fabio.sabatini@uniroma1.it

1 The paper benefited from comments by participants at the ERF 20th Annual Conference: Economic Development and Social Justice (Cairo, Egypt, March, 2014), at the seminar of the London Centre for Corporate Governance and Business Ethics (London, January 31, 2014) at the $25^{\text {th }}$ Annual EAPE Conference 2013 'Beyond Deindustrialisation: the Future of Industry' (Paris, France, November 7-9, 2013), at the Fourth Annual Conference in Political Economy 'Political Economy, Activism and Alternative Economic Strategies' (The Hague, The Netherlands, July 9-11, 2013) and at research seminars in London and Rome. An initial version of the paper is under the ERF working paper series N.841. We are grateful to two anonymous reviewers whose suggestions allowed a substantial improvement of the paper. We thank the Palestine Economic Policy Research Institute (MAS) for sharing data for the measurement of social capital in the Palestinian Territories. We are deeply indebted to Jamil Hilal, Klaus Nielsen and Hadi Salehi Esfahani for precious comments and suggestions. Usual caveats apply.
} 
et al., 2008: 456). Weak public institutions discourage mutual confidence and prosocial behaviour in prisoners' dilemma-like situations (Bühlmann and Freitag, 2009; Dasgupta, 2005; Frey and Torgler, 2007; Letki, 2006). The empirical literature identifies the belief that unknown others can be trusted (usually called 'social', 'generalized' or 'moral' trust) as being one of the best predictors of prosocial behaviour, especially in 'individualist' societies - i.e. those societies where social relations mainly rely on weak ties and are informed by values related to power, achievement and self-direction (Hofstede, 1991; Irwin, 2009; Oishi et al., 1998). In 'collectivist' societies, where social relations rely on strong, cohesive group ties informed by principles of tradition, conformity and benevolence (Hofstede, 1991; Triandis, 1995), confidence in public institutions has been found to play a stronger role in promoting cooperation (Kumlin and Rothstein, 2005; Yamagishi, 1988). In these societies, citizens tend neither to trust nor to cooperate with people outside of their reference groups - usually only composed of the extended family and close friends. Institutional trust, intended as citizens' confidence in the fairness and efficiency of public institutions, can provide individuals with valid incentives to behave prosocially - e.g. to avoid cheating in transactions - even in settings of low or decreasing generalized trust, for example by strengthening the belief that anti-social behaviours will be properly punished.

This paper aims to empirically investigate the determinants of prosocial behaviour in the Palestinian territories, with a special focus on the role of different types of trust. To reach this goal, we rely on a unique dataset collected through the administration of a questionnaire to a representative sample of 2,508 Palestinian households in the West Bank (including Jerusalem) and the Gaza Strip in June and July 2007 by the Palestinian Central Bureau of Statistics.

The Palestinian Territories are characterized by a typical collectivist society coping with a difficult process of state capacity building in a context of low generalized trust and strong uncertainty about the future: Israeli closure policy has compromised Palestinian workers' ability to work in Israel and causes continuous fluctuations in prices and transaction costs, leading to a substantial inability to undertake basic economic activities (European Commission, 2004; 2011). As a result, in addition to dramatic macroeconomic implications in terms of labour force participation, unemployment, standards of living, poverty and deterioration of human capital, the social mechanisms for the efficient resolution of prisoners' dilemma-like situations are weak, agents' behaviour in strategic contexts is hardly predictable, and economic transactions between unknown parties take place in a climate of general distrust. The uncertainty pervading the economic environment is a decisive factor of the economic backwardness which further hampers the process of state capacity building. On the other hand, Palestinian society seems to remain relatively cohesive. As stated in a World Bank report, 'Despite violence, economic hardship and the daily frustrations of living 
under curfew and closure, lending and sharing are widespread and families for the most part remain functional ... The West Bank and Gaza has/have absorbed levels of unemployment that would have torn the social fabric in many other societies' (World Bank, 2003: 6).

The collectivist aspects of Palestinian society - such as strong family ties and informal networks, commonly known as 'bonding social capital' (Putnam et al., 1993) - play a crucial role in building resilience to conflict (Nasr and Hilal, 2007; World Bank, 2003). However, bonding social capital also prevents group members from trusting (and cooperating with) outsiders (Field, 2004; Putnam et al., 1993; Sabatini, 2008). In addition to the achievement of peace, the promotion of prosocial behaviour outside of the small boundaries of reference groups is a necessary (though not sufficient) task for the advancement of the economic, social and political development of the Territories.

In this paper, we investigate the possible role of trust in prosocial behaviour in two steps: first, we draw on a number of attitudinal items to build indicators of unobserved attitudes such as institutional trust and prosociality through a measurement model. Second, the correlation between latent measures of trust and prosocial attitudes is assessed through a structural equations model (SEM) and some refinements.

SEM estimates indicate a significant and positive correlation between trust in domestic institutions, such as public institutions, clans and the rule of law and prosocial attitudes. Trust in international institutions seems to play a minor role in prosociality. To interpret these results, we borrow the concept of 'psychological contract' from the organizational behaviour literature (Rousseau, $1989 ; 1995)$ to argue that there is an implicit agreement between citizens and institutions based on mutual obligations. Our results suggest that citizens who perceive institutions as efficient and fair want to act prosocially to 'fulfil the contract'. If institutions are perceived as inefficient and corrupt, institutional trust decreases and prosocial behaviour is discouraged, because citizens neither want to respect obligations (e.g. in paying taxes) nor do they fear being sanctioned for their anti-social behaviour (e.g. inefficient public institutions will find it difficult to properly punish tax evasion).

In a collectivist society endemically lacking generalized trust, a decrease in institutional trust may compromise social order, especially in the course of a difficult process of state capacity building. The strengthening of institutional trust may also reinforce the 'psychological contract' between the state and its citizens in Western democracies, or more in general in individualist societies, where a decline in generalized trust has been documented by empirical studies (Antoci et al., 2013; Putnam, 2000; Sarracino, 2010). Political science studies have highlighted how inclusive and efficient welfare state institutions tend to increase social and institutional trust (Bühlmann and Freitag, 2009; Kumlin and Rothstein, 2005; Rothstein, 2001). Our findings add to this 
literature by suggesting that governments, by designing efficient and fair state institutions, can invest in social and institutional trust and encourage prosocial behaviour.

The outline of the paper is as follows: Section 2 presents the motivation of the study and briefly reviews the related literature. Section 3 describes our data and reports some descriptive statistics. The empirical analysis of the role of different types of trust in prosocial attitudes is presented and discussed in Section 4, along with some model refinements. Concluding remarks and a brief discussion of implications for policy and future research close the paper.

\section{Motivation of the study and related literature}

Since the early 1990s, a growing number of studies have identified social capital - with particular regard to its 'cognitive' dimension of social trust and its 'structural' aspect of prosocial behaviour - as a factor of economic and social development. Following Uphoff (1999), it is possible to distinguish between structural and cognitive dimensions of social capital. Structural social capital deals with individuals' behaviours and mainly takes the form of networks and associations that can be observed and measured through surveys. Cognitive social capital derives from individuals' perceptions resulting in norms, values and beliefs that contribute to cooperation. These latter aspects involve subjective evaluations of the social environment. Both structural and cognitive dimensions include several sub-dimensions whose relationship with outcome variables in turn varies depending on the context and on the effect of other individual and local potentially influential factors (Degli Antoni, 2009; Yamamura, 2011). Trust and prosocial behaviour have been credited with reducing transaction costs, promoting the enforcement of contracts, facilitating credit at the level of individual investors and encouraging innovation and investment in human and physical capital (see among others Christoforou, 2010; Knack and Keefer, 1997; Zak and Knack, 2001).

Knack (2002: 171) argues that, 'Where social mechanisms for the efficient resolution of prisoners' dilemma and principal-agent games are weak or absent (i.e. where most potential pairs of economic transactors cannot trust each other) the private returns to predation increase while the private returns to production fall'. Individuals in higher-trust societies indeed spend less on protecting themselves from being exploited in economic transactions (Knack and Keefer, 1997).

Even if these views have been acknowledged in the economics debate only recently, it is worth noting that the concept of the social 'embeddedness' of the economic action is deeply rooted in the history of economic thought, and can also be found in the early work of classical economists. Typical code-words of the social capital literature (e.g. trust, altruism, sympathy and prosocial 
behaviour) can be found in the work of Adam Smith. In the Theory of Moral Sentiments, Smith (1759) argued that there were certain virtues, such as trust and a concern for fairness that, due to their role in prosocial behaviour and in the discouragement of cheating, were vital for the functioning of a market economy. Smith described trust and prosocial behaviour as critical foundations of the early beginnings of the market, allowing the development of trade and economic activities. According to North (1990: 54), 'The inability of societies to develop effective, low-cost enforcement of contracts is the most important source of both historical stagnation and contemporary underdevelopment in the Third World'. In our view, it is reasonable to extend this point by arguing that not only the effective functioning of markets but also, to a larger extent, the resilience of the economic system, rely on those institutions (whether formal or informal) that foster the sharing and diffusion of feelings of trust and promote or preserve prosocial behaviour.

Disentangling the determinants of prosocial behaviour, and its relationship with trust, is a fundamental task for economic research, which assumes particular importance in the analysis of a process of state capacity building, where markets and formal public institutions are in the early stages of their development. From this point of view, the Palestinian society poses a puzzle because, despite a very low generalized trust, forms of prosocial behaviour remain functional within groups, helping to preserve minimum acceptable levels of well-being in a strongly unfavourable macroeconomic and political scenario. Prosocial behaviour, however, still seems to remain the exception between groups (or individuals belonging to different groups). One of the challenges of the process of state capacity building will be the preservation of in-group cohesion and wellbeing, and the development of policy actions to foster cooperative behaviours between groups and organizations.

Irwin (2009) argues that, in collectivist societies, prosocial behaviour is affected by institutional trust (intended as the belief that institutions effectively induce others to act in a trustworthy manner) rather than generalized trust as in individualist cultures (Brehm and Rahn, 1997; Uslaner, 2002; Yamagishi and Yamagishi, 1994).

In collectivist cultures, relationships are guided by rigid distinctions between in-group and out-group. Individuals are tightly linked to their group, which protects them throughout their life span in exchange for unquestioning loyalty. People are expected to maintain harmony with the in-group through reciprocally cooperative interactions. To accomplish this, collectivism generally entails a strong emotional dependence on the group, which controls individual behaviour through social patterns and rules based on principles of tradition, conformity, benevolence and respect (Berigan and Irwin, 2011; Irwin, 2009; Triandis, 1995). Personal aspirations are often sacrificed to the pursuit of the group's welfare (Berigan and Irwin, 2011; Hofstede, 1991). Collectivist societies are naturally based on extended families or clans. Researchers typically agree that 
Western cultures are individualistic while Asian, Latin American and Middle Eastern cultures are collectivistic (Buda and Elsayed-Elkhouly, 1998; Hofstede, 1991).

Yamagishi (1998) find that, due to the importance individuals place on in-groups compared to out-groups, people from collectivist societies display markedly less trust in strangers than those from individualist societies (Yamagishi and Yamagishi, 1994). Still Yamagishi (1988) shows, that this lack of trust has a negative effect on prosocial behaviour toward strangers.

Irwin (2009) uses World Values Survey (WVS) data from 14 countries for the period 1981-2001 to assess the role of social and institutional trust in individuals' prosocial behaviour. To test his hypotheses on the diverse roles of different types of trust, the author segments countries according to their respective levels of individualism or collectivism, as measured by the Hofstede-scale (Hofstede, 1991). The empirical results suggest that individuals of collectivist societies rely mainly on public institutions to protect them from potential noncooperative behaviours of out-group strangers. The effectiveness and fairness of public institutions in fact increase individuals' confidence that cheating will be unfailingly punished and that unknown others will behave cooperatively.

Institutional trust, i.e. the confidence in the fairness and efficiency of public institutions, can be seen as the outcome of a complex, long-running and continuous interaction between the state and its citizens. This interaction is more likely to be cooperative in the presence of a certain degree of reciprocity between the parties: individuals trust institutions and avoid cheating only if they expect these institutions will act fairly and effectively.

The literature explains this mechanism through two main arguments.

The first argument, advanced by Kumlin and Rothstein (2005), stresses the idea that the positive perception that people have of public institutions increases people's confidence in the society and their trust in their fellow citizens. Drawing on cross-sectional data collected in 1999 in Western Sweden by the SOM Institute at Göteborg University, the authors found that social trust is higher among people with more confidence in public officials and the welfare state's institutions.

The second argument focuses on the idea that trustworthy institutions may reinforce prosocial behaviour by increasing citizens' confidence that cheating actions will be discovered and effectively punished (Irwin, 2009).

Several empirical studies have found a significant and positive correlation between the belief that strangers can be trusted and institutional trust - intended as trust in public institutions. It seems reasonable to argue that citizens who report high levels of confidence in public institutions may also be more confident that wrongdoers will be punished.

The arguments outlined above lead us to formulate the hypothesis that, in the collectivist society of Palestinian territories, institutional trust - defined as confidence in public institutions - may be a better predictor of prosocial behaviour than other forms of trust. 


\section{Data and methods}

As anticipated in the introduction, data were collected through the administration of a questionnaire to a representative sample of the population ( $n=2,508)$ of the West Bank and the Gaza Strip in June and July 2007 by the Palestinian Central Bureau of Statistics. The questionnaire was specifically designed to assess civic and political participation, engagement in formal and informal networks, various forms of trust, shared values and attitudes on contemporary social and political issues (Nasr and Hilal, 2007). ${ }^{2}$

Following SEM practice, we first drew on a number of attitudinal items to build three latent constructs: prosocial behaviour, trust in public institutions, and trust in international institutions. The correlation between these constructs was then analysed through a structural model, also accounting for a number of control variables.

Prosocial behaviour (labelled as prosocial) is obtained as a combination of responses to questions about whether each of the following behaviours 'can always be justified, never be justified or something in between':

(1) Absence from work without good reasons (work)

(2) Bribery (bribe).

(3) Abstention in elections (abstention). ${ }^{3}$

(4) No commitment to traffic rules (traffic).

(5) Purchase of stolen goods (stolen).

Respondents chose a number from 1 (never justifiable) to 3 (always justifiable). We reversed this scale, so that larger values indicate a greater propensity for prosocial behaviour. Descriptive statistics are presented in Table 1.

Due to the large sample size and to non-normal distributed data, in order to achieve a better empirical fit we employed a measurement model based on generalized least square (see Olsson et al., 2000). Figure 1 describes the measurement model used to construct the latent indicator of prosocial attitudes.

We obtained an unobserved factor which is significantly and positively correlated with all the observed indicators. The correlation matrix and regression weights are reported in Tables A1 and A2 in the Appendix. Squared multiple correlations (reported in Table A3 in the Appendix) indicate that the unobserved factor explains more than $30 \%$ of the variance of work and stolen, and about $20 \%$ of the remaining items bribe and abstention.

2 As pointed out by Nasr and Hilal 'Differently from the West Bank the analysis of data from the Gaza Strip could only be conducted at the level of the Strip's population as a whole, since the political and security situation prevented from stratifying the sample at the more detailed level of sub-groups defined by demographic characteristics' (Nasr and Hilal, 2007: 2).

3 This refers to the abstention in the 2006 elections for the Palestinian Legislative Council (Nasr and Hilal, 2007). The 2006 elections were the second parliamentary elections after those in 1996. The 2006 PLC elections were preceded by the Presidential elections in January 2005. 
Table 1. Descriptive statistics

\begin{tabular}{lllllll}
\hline \hline & n. obs. & Mean & Std. Dev. & Min & Max & Range \\
\hline Work & 1,098 & 2.69 & 0.579 & 1 & 3 & 2 \\
Bribe & 1,098 & 2.95 & 0.248 & 1 & 3 & 2 \\
Abstention & 1,098 & 2.30 & 0.737 & 1 & 3 & 2 \\
Traffic & 1,098 & 2.84 & 0.406 & 1 & 3 & 2 \\
Stolen & 1,098 & 2.87 & 0.394 & 1 & 3 & 2 \\
Trust_gov & 1,098 & 2.06 & 1.008 & 1 & 4 & 3 \\
Trust_parties & 1,098 & 2.08 & 0.935 & 1 & 4 & 3 \\
Trust_localgov & 1,098 & 2.49 & 0.926 & 1 & 4 & 3 \\
Trust_parliament & 1,098 & 2.21 & 0.996 & 1 & 4 & 3 \\
Trust_president & 1,098 & 2.28 & 1.014 & 1 & 4 & 3 \\
Trust_judicial & 1,098 & 2.43 & 0.978 & 1 & 4 & 3 \\
Trust_police & 1,098 & 2.52 & .968 & 1 & 4 & 3 \\
Trust_un & 1,098 & 2.29 & 1.035 & 1 & 4 & 3 \\
Trust_intorganization & 1,098 & 2.17 & 0.987 & 1 & 4 & 3 \\
Trust_donors & 1,098 & 2.23 & 1.067 & 1 & 4 & 3 \\
Trust_clan & 1,098 & 3.22 & 0.751 & 1 & 4 & 3 \\
Trust_specific & 1,098 & 6.24 & 1.193 & 2 & 8 & 6 \\
Rule_law & 1,098 & 2.92 & 0.313 & 1 & 3 & 2 \\
\hline \hline
\end{tabular}

Figure 1. (Colour online) Measurement model of prosocial.

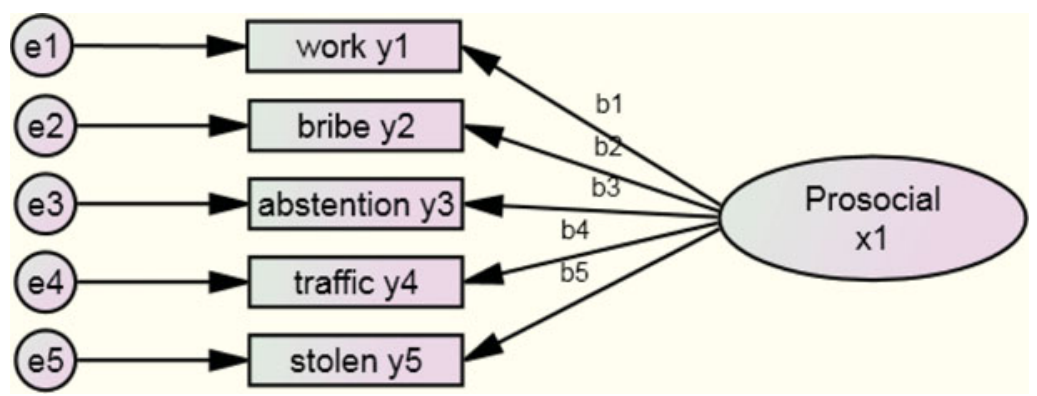

Due to the large sample size, the Chi-square model is not a reliable goodnessof-fit measure (Bollen, 1989; Kline, 2005), we therefore followed Tempelaar et al. (2007) and rely on alternative fit indexes which are reported in Table A4 in the Appendix. All relative fit indicators are above the minimum threshold and all absolute fit indicators are below the value of the threshold level identified by the literature (Bollen, 1989; Kline, 2005).

Institutional trust is measured by two latent variables obtained as combinations of indicators of respondents' trust in public and international institutions. In the questionnaire, trust in public institutions is measured by the score from 1 to 4 given by respondents to the question: 'Do you think that the following institutions can be trusted?', 1 meaning 'Totally' and 4 meaning 'Not at all'. The named institutions were the government (trust_gov), ${ }^{4}$

4 The term government mentioned in the questionnaire refers to the Palestinian Authority. 
Figure 2. (Colour online) Measurement model trust.

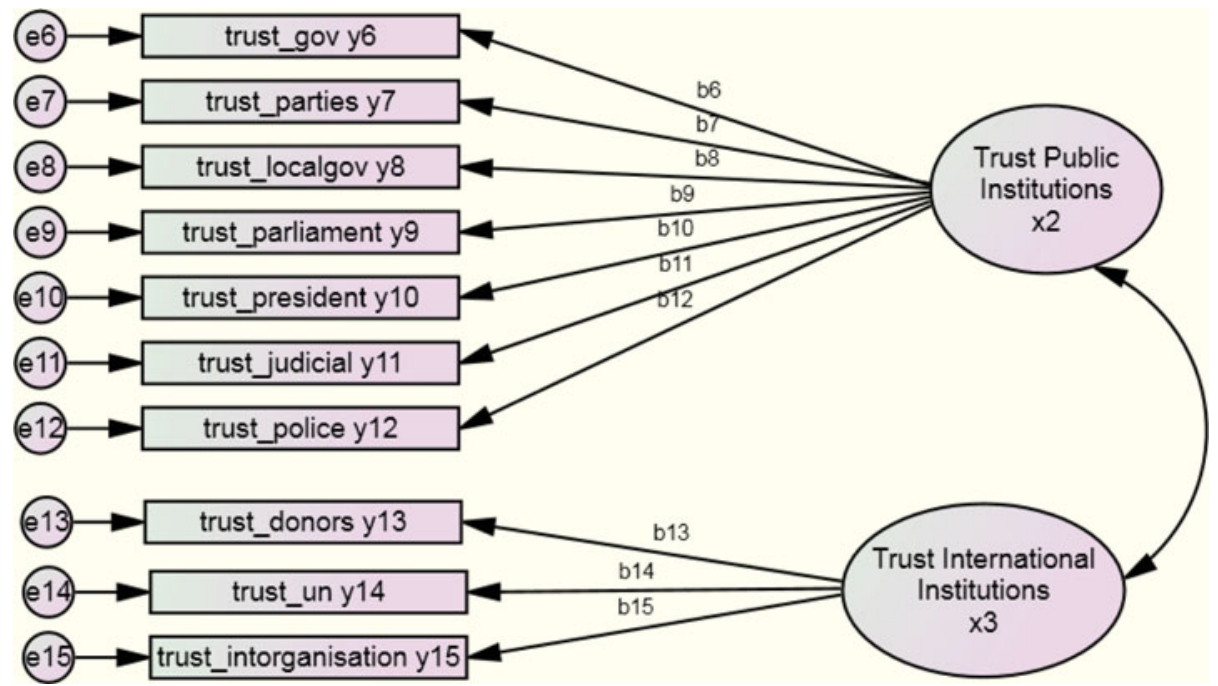

political parties (trust_parties), the local government (trust_localgov), the president of the Palestinian National Authority (trust_president), ${ }^{5}$ the Parliament (trust_parliament), the judicial system (trust_judicial) and the police (trust_police).

On the other hand, trust in international institutions refers to international donors (trust_donors), international organizations linked to the United Nations (UN) (trust_un) and international organizations not linked to the UN (trust_intorganizations). We reversed the original scale, so that larger values indicate greater trust.

Figure 2 describes the measurement model we used to build the latent indicators of trust in public and international institutions.

Similarly, with the measurement model of prosocial, here the latent variables of trust in public and international institutions are related to their respective multiple observable indicators.

Correlation matrices, regression weights and goodness-of-fit indexes are reported in Tables A5, A6 and A7 in the Appendix.

Table A6 indicates that the regression weights between the latent variables and the observable items are all positive and significant at $1 \%$ significance level. The standardized regression weights of the latent indicator of trust in international institutions on the trust items reported in Table A9 are largely above 0.7 . This means that a 1 unit increase in the standard deviation of the latent variable is associated with an increase of more than 0.7 unit of standard deviation of the

5 This is the highest institutional position. The constitution requires that the President is legitimated to appoint the Prime Minister of the Palestinian Authority. Among his/her responsibilities, the President is the chief of the Palestinian forces. 
trust items. The standardized regression weights of the variable trust in public institutions on the trust items reported in Table A9 are largely above 0.5 except in the case of trust in government where the standardized regression weight is 0.47 .

The covariance between the latent variables is significant at $1 \%$ significance level. The squared multiple correlations (reported in Table A8) indicate that the latent indicator of trust in international institutions explains approximately $67 \%$ of the variance of trust in donors in the UN and about approximately $75 \%$ of the variance of respondents' trust in non-UN international organizations. The latent indicator of trust in public institutions explains a proportion ranging from $21 \%$ to $59 \%$ of the variance of basic indicators of institutional trust.

We also control for knowledge-based trust, trust in clans and the importance attributed to the rule of law. The social psychology literature identifies two main types of trust, 'social' (or 'generalized' or 'moral') trust, and 'knowledgebased' (or 'particularized') trust (see Uslaner, 2002, for a comprehensive review). Unfortunately, we were not able to include generalized trust in the model, since this variable was measured by the Palestinian Central Bureau of Statistics as a binary indicator obtained by 'yes' or 'no' responses to the question: 'Generally speaking, do you think that most people can be trusted?'. ${ }^{6}$

Generalized trust is distinct from knowledge-based trust, which depends on information and experience (Yamagishi and Yamagishi, 1994). According to Dasgupta (2000), we trust people mainly when we know something about their disposition, their available options, their ability and so forth, so we think they are trustworthy and expect they will choose to behave themselves. Knowledgebased trust is the confidence in known people and in people holding a similar status, such as relatives, friends and colleagues. This form of trust is rooted in strong ties, such as those embedded in Palestinian family clans, or may develop over time with business exchange (Ring and van de Ven, 1992; Zucker, 1986) and plays a fundamental role in preserving economic activities, especially in the context of small communities such as Palestinian clans.

Knowledge-based trust (trust_specific) is measured by the score from 1 to 4 given by respondents to the questions: 'Do you think that your neighbours can be trusted?' and 'Do you think that your colleagues can be trusted?', 1 meaning 'Totally' and 4 meaning 'Not at all'. As for previous indicators, we reversed the scale, so that larger values indicate greater trust. Our indicator is built as the

6 The use of binary variables may produce unreliable estimates in SEMs (Kline, 2005). It is worth noting that measures of generalized trust based on this question has been criticized in the literature due to their ambiguity with respect to which 'people' respondents have in mind. As stated by Knack and Keefer (1997), responses could easily reflect a varying mix of two concepts across individuals: how much trust one places in people who are not close friends or relatives, and the frequency of encounters with such persons. People in low-trust environments such as the Palestinian territories will transact more with close friends and relatives than with strangers, compared with people in high-trust environments such as most individualist societies. 
arithmetical sum of the two scores. Trust in clans (trust_clan) is measured by the 1-4 score (recoded as for previous variables) given to the question: 'How much confidence do you have in the family clan?'.

The importance of the rule of law (rule_law) is measured by the 1-4 score (as in the previous variables) given to the question: 'Which is the importance of the rule of law?'

The relationships between prosocial behaviour and the various forms of trust are assessed by means of a SEM and some refinements. The advantage of SEM over separate regression models for each outcome is twofold. First, as noted by Kupek (2006: 8), 'SEM can model all regression equations simultaneously, thus providing a flexible framework for testing a range of possible relationships between the variables in the model, including mediating effects and possible latent confounding variables. Second, on a more general level, SEM parameters can quantify the contribution of each predictor to the covariance structure such as the common factors model'. Moreover, SEM allows the researcher to better account for possible causes of common bias affecting the main variables of the analysis by the estimation of possible correlations among error terms.

We follow the conventional practice of indicating endogenous variables with $\eta$ and exogenous variables with $\xi$. Error terms are indicated with the symbol $\xi$. The prosocial attitudes of individual $j$ can be expressed as:

$$
\eta_{j}=\alpha+\mathrm{B} \eta_{j}+\Gamma \xi_{j}+\zeta_{j}
$$

where $\alpha$ is an intercept vector, $\boldsymbol{B}$ a matrix of structural parameters governing the relations among the endogenous variables, $\boldsymbol{\Gamma}$ a regression parameter matrix for regressions of endogenous variables on exogenous explanatory variables and $\xi_{j}$ a vector of disturbances. More specifically, in the model presented in this section, we only estimate a limited number of parameters as reported in Table 1 below. ${ }^{7}$ Modification indexes were used to add or subtract parameters one at time in order to achieve a better fit to the data. The path diagram of the model presented in this section is represented in Figure 3.

\section{Empirical results}

Before illustrating the SEM results, it is interesting to report some descriptive evidence. Table 2 ranks institutions based on the percentage of citizens reporting the highest trust score. $12.34 \%$ of our sample report having great trust in the

\footnotetext{
7 While designing the structural model, the researcher puts forward a number of hypotheses on the linkages connecting the phenomena under consideration. The consistency of these hypotheses with the pattern of variances and covariances in the data is then assessed through the goodness-of-fit tests. In practice, this approach combines exploratory and confirmatory purposes: first, a model is theorized and tested using SEM procedures. If it is found to be deficient, an alternative model is then tested based on changes suggested by modification indexes. Changes may consist, for example, in the addition of parameters to (or the subtraction from) matrixes $B$ and $\Gamma$.
} 
Table 2. Ranking of the institutions according to trust

\begin{tabular}{lll}
\hline \hline Ranking & Institutions & $\%$ of respondents having great trust in this institution \\
\hline 1 & Family clan & $40.32 \%$ \\
2 & Police & $12.34 \%$ \\
3 & Judicial system & $11.75 \%$ \\
4 & Local government & $11.01 \%$ \\
5 & President & $10.60 \%$ \\
6 & Parliament & $8.68 \%$ \\
7 & Government & $7.98 \%$ \\
8 & Political parties & $3.89 \%$ \\
\hline \hline
\end{tabular}

Figure 3. (Colour online) Structural model.

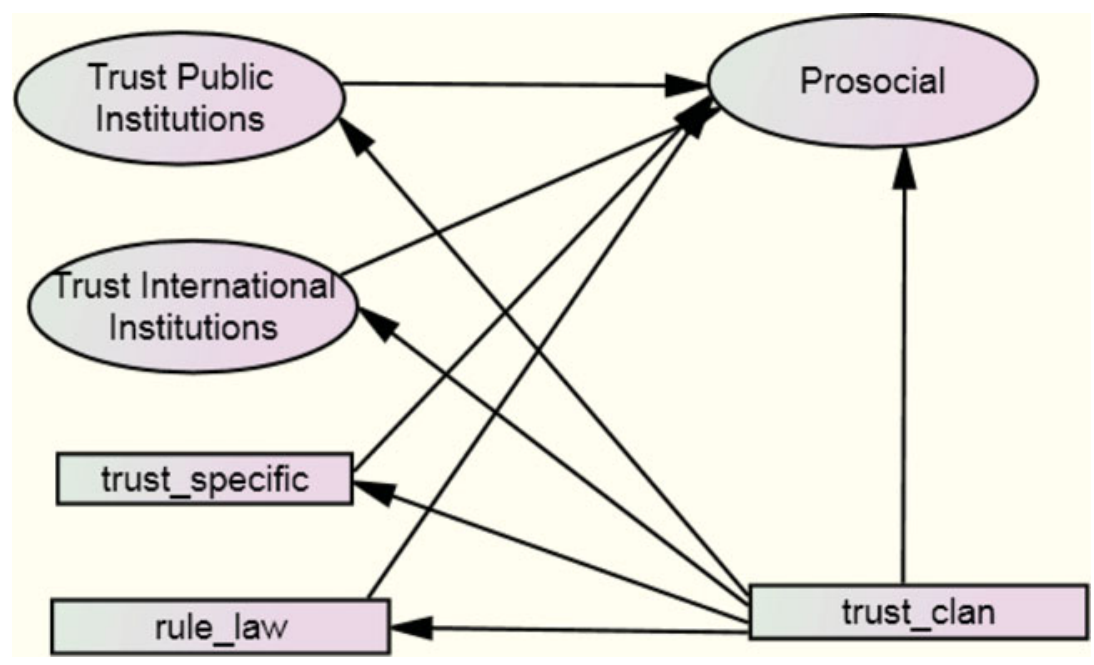

police while only $3.89 \%$ of respondents report great confidence in political parties.

Family clans appear to be more popular than formal political institutions. $40.32 \%$ of Palestinians in our sample declare they have total trust in family clans. The highest level of trust in clans is more frequently observed among males $(42.91 \%)$ than females $(37.73 \%)$. The analysis of correlations indicates that trust in clans is significantly and positively correlated with the age of the respondents

Table 3 reports results of Chi-square tests between trust in different institutions, gender and active political participation. Compared to males, a smaller proportion of females report the highest level of confidence in the institutions representing the entire Territories such as the Parliament, the Government and the President, compared with male respondents. However, it also shows a smaller proportion of females do not trust these institutions at all. 
Table 3. Trust in political institutions by gender and political participation

\begin{tabular}{|c|c|c|}
\hline Trust Institutions/characteristics & Gender & Individuals politically active \\
\hline \multirow[t]{2}{*}{ Trust a lot police } & Female: $10.71 \% * * *$ & Active: $16.25 \% * * *$ \\
\hline & Male: $13.91 \% * * *$ & Not active: $10.74^{* * *}$ \\
\hline \multirow[t]{2}{*}{ Not trust police } & Female: $23.88 \% * * *$ & Active: $23.93^{* * *}$ \\
\hline & Male: $26.81 \% * * *$ & Not active: $26.06^{* * *}$ \\
\hline \multirow[t]{2}{*}{ Trust a lot judicial system } & Female: $10.99 \% * * *$ & Active: $16.44 \%{ }^{* * *}$ \\
\hline & Male: $12.48 \% \%^{* * *}$ & Not active: $9.78 \% \%^{* * *}$ \\
\hline \multirow[t]{2}{*}{ Not trust judicial system } & Female: $22.43 \% * * *$ & Active: $25.04 \% * * *$ \\
\hline & Male: $29.73 \% * * *$ & Not active: $26.71 \% * * *$ \\
\hline \multirow[t]{2}{*}{ Trust a lot local government } & Female: $12.03 \%$ & Active: $11.40 \% * * *$ \\
\hline & Male: $10.07 \%$ & Not active: $10.89 \% * * *$ \\
\hline \multirow[t]{2}{*}{ Not trust local government } & Female: $20.81 \%$ & Active: $18.71 \%{ }^{* * *}$ \\
\hline & Male: $24.08 \%$ & Not active: $24.16 \% * * *$ \\
\hline \multirow[t]{2}{*}{ Trust a lot President } & Female: $8.73 \%{ }^{* * *}$ & Active: $15.09 \% * * *$ \\
\hline & Male: $12.33 \% \%^{* * *}$ & Not active: $8.64 \%{ }^{* * *}$ \\
\hline \multirow[t]{2}{*}{ Not trust President } & Female: $30.00 \% * * *$ & Active: $31.07 \% * * *$ \\
\hline & Male: $38.25 \%{ }^{* * *}$ & Not active: $35.68 \% \%^{* * *}$ \\
\hline \multirow[t]{2}{*}{ Trust a lot Parliament } & Female: $7.73 \%{ }^{* * *}$ & Active: $9.88 \% * * *$ \\
\hline & Male: $9.56 \% * * *$ & Not active: $8.09 \%{ }^{* * *}$ \\
\hline \multirow[t]{2}{*}{ Not trust Parliament } & Female: $29.66 \% * * *$ & Active: $36.14 \% *$ \\
\hline & Male: $37.74 \%{ }^{* * *}$ & Not active: $32.96 \%{ }^{*}$ \\
\hline \multirow[t]{2}{*}{ Trust a lot Government } & Female: $6.84 \%^{* * *}$ & Active: $8.64 \% *$ \\
\hline & Male: $9.04 \% * * *$ & Not active: $7.61 \% *$ \\
\hline \multirow[t]{2}{*}{ Not trust Government } & Female: $39.6 \% * * *$ & Active: $45.45 \% *$ \\
\hline & Male: $44.27 \% * * *$ & Not active: $40.72 \%{ }^{*}$ \\
\hline \multirow[t]{2}{*}{ Trust a lot political parties } & Female: $3.16 \%$ & Active: $6.94 \% * * *$ \\
\hline & Male: $4.56 \%$ & Not active: $2.51 \% * * *$ \\
\hline \multirow[t]{2}{*}{ Not trust political parties } & Female: $39.69 \%$ & Active: $35.60 \% * * *$ \\
\hline & Male: 40.55 & Not active: $42.18 \% * * *$ \\
\hline
\end{tabular}

$*, * *, * * *$ indicate respectively $10 \%, 5 \%$ and $1 \%$ significance level of the Chi-squared test.

Tests also indicate a systematic and significant association between trust in institutions and political participation. The proportion of those who totally trust institutions is higher among the politically active.

A statistical analysis conducted through Chi-squared estimations indicates that Palestinians appear to be reluctant toward the 'heaviest' anti-social behaviours such as bribery and the purchase of stolen goods. In fact, about $90 \%$ of the sample $(90.67 \%$ female $88.17 \%$ males) does not accept the purchase of stolen goods and approximately $96 \%$ do not accept bribery. Females are slightly more reluctant in justifying more to accept mild forms of anti-social behaviours than men: $78.26 \%$ of women do not accept absence from work without good reasons compared with $76.18 \%$ of men, and $87.45 \%$ of women do not agree with the lack of commitment to traffic regulations against $82.95 \%$ of men. Palestinians seem to be more tolerant towards abstention at elections, which is 
Table 4. GLS estimates of the structural equation model

\begin{tabular}{|c|c|c|c|c|c|}
\hline & Prosocial & Trust public. inst. & Trust intern. inst. & Rule of law & Trust specific \\
\hline Trust public inst. & $\begin{array}{c}0.059^{* *} \\
(0.029)\end{array}$ & & & & \\
\hline Trust intern. inst. & $\begin{array}{c}0.018 \\
(0.017)\end{array}$ & & & & \\
\hline Trust clan & $\begin{array}{c}0.021 \\
(0.018)\end{array}$ & $\begin{array}{l}0.175^{* * *} \\
(0.026)\end{array}$ & $\begin{array}{l}0.125^{* * *} \\
(0.038)\end{array}$ & $\begin{array}{c}0.020 \\
(0.013)\end{array}$ & $\begin{array}{l}0.663^{* * *} \\
(0.044)\end{array}$ \\
\hline Rule of law & $\begin{array}{c}0.095^{* *} \\
(0.040)\end{array}$ & & & & \\
\hline Trust specific & $\begin{array}{c}0.023^{*} \\
(0.012)\end{array}$ & & & & \\
\hline
\end{tabular}

Table 5. Measures of fit

\begin{tabular}{lccccccc}
\hline \hline Indicators & CMIN/DF & RMSEA & SRMR & GFI & AGFI & IFI & CFI \\
\hline Cut-off value & $<5$ & $<0.08$ & $<0.1$ & 0.9 & 0.9 & 0.9 & 0.9 \\
Level of this analysis & 2.23 & 0.033 & 0.039 & 0.97 & 0.96 & 0.91 & 0.90 \\
\hline \hline
\end{tabular}

frowned upon by $48.6 \%$ of females and $48.25 \%$ of males. This proportion is slightly lower, $46.79 \%$, among Palestinians with a higher-level of education.

The SEM analysis shows that our latent measure of prosocial attitudes is significantly and positively correlated with institutional trust, with trust in clans and with the importance attributed to the rule of law (see Table 4). Goodness-offit indicators are reported in Table 5. All the indicators of fit satisfy the respective threshold minimum and maximum limits.

The correlation between the main endogenous variable and our measure of knowledge-based trust is only slightly significant.

This result provides support to the hypothesis that, in collectivist societies, institutional trust plays a greater role than knowledge-based trust in providing incentives to avoid cheating and to behave prosocially. Knowledge-based trust, in fact, depends on experience and is strictly related to individuals' involvement in small networks - such as family clans - acting as forms of 'bonding social capital' and encouraging members to behave cooperatively with their in-group peers and to distrust (and possibly exploit) outsiders. Institutional trust, on the other hand, can provide incentives to prosocial behaviour through two main channels.

Firstly, individuals will be less fearful of being cheated in interactions, especially transactions, if they are confident that institutions are capable of enforcing contracts, effectively resolving disputes, and possibly punishing offenders. This makes outsiders' behaviour more predictable causing an overall 
reduction in uncertainty, at least in the perception of those who trust institutions and who are thereby encouraged to act cooperatively. Secondly, the cooperative behaviour of individuals who trust institutions may be a matter of reciprocity. As outlined in the brief review in Section 2, several studies show that citizens tend to act prosocially if they feel they are being fairly treated by public institutions.

In addition to these two explanations, citizens may also act prosocially because they are tied to public institutions by a 'psychological contract' based on mutual obligations. People who think that institutions are efficient and fair are likely to report high levels of institutional trust and may choose prosocial behaviour with the aim of fulfilling the psychological contract.

The concept of psychological contract refers to the mutual beliefs, perceptions and informal obligations between an employer and an employee (Rousseau, 1989; 2004). It is a common view in the organizational behaviour literature that employees tend to maximize their efforts and behave cooperatively only as far as their expectations of their employer's fairness are fulfilled (Aselage and Eisenberger, 2003; Robinson and Rousseau, 1994). The notion of psychological contract can be extended to other principal-agent-like scenarios. Feld and Frey (2002) argue that the relationship between tax authorities and taxpayers involves an implicit or psychological contract. 'The more strongly the political participation rights are developed, the more important this contract is, and the higher tax morale is. The existence and survival of this tax contract requires certain behaviour on the part of the two parties concerned'. This argument also relies on the concept of procedural justice: according to the authors, 'The tax authorities must acknowledge and support the contract with the taxpayers by acting in a respectful way towards them, but also by preventing honest taxpayers from being exploited in the process' (Feld and Frey, 2002: 89). A number of subsequent empirical studies on tax morale report a positive impact on institutional trust on tax compliance across different contexts, such as Latin America (Torgler, 2005a), Switzerland (Torgler, 2005b) and Europe. In these cases, institutional trust refers to formal public organizations including confidence in government (Torgler and Schneider, 2007), in the President (Torgler, 2005a; 2005b), in the Parliament (Martínez-Vázquez and Torgler, 2009) and in the legal system (Torgler and Schneider, 2007).

Whether the relationship involves an employer and his/her employees or the state and its citizens, the social exchange between the parties and the fulfilment of the contract essentially rely on trust. Our results support the view that, in collectivist societies, trust towards domestic political institutions plays a greater role than other forms of trust.

The reciprocity argument also entails that people who think that institutions are unfair and untrustworthy may choose anti-social behaviour as a reaction of the government's lack of respect of the psychological contract. Anti-sociality, on the other hand, may be seen as a way to cope with unfavourable social and economic conditions when public institutions fail to preserve civil rights and 
deliver public goods. For example, individuals often explain the act of bribing as the only route to obtaining access to basic public services, like receiving medical attention or issuing a certificate. Similarly, not paying taxes can be seen by individuals as an effort to sustain a subsistent level of living that public institutions fail to preserve. ${ }^{8}$

In the Palestinian territories, in addition to formal public institutions, clans and international institutions should also be considered. International NGOs play a crucial role in the Palestinian economy. As reported by Lasensky (2004), Palestinians are probably the largest per capita recipients of international aid. Donors and international organizations provide fundamental support in the provision of important public services such as education and food security.

Our estimates, however, interestingly do not show a significant role of trust in international institutions in prosociality. Trust in clans, on the other hand, is found to be significantly and positively correlated with our latent measures of institutional trust. Clans are in fact one of the pillars of Palestinian community governance. In the Territories, clans (hamail) are family-based associations whose members do not necessarily need to be relatives. These associations usually group several extended families that might be connected through a common tribal father (Atran, 1986; Crisis Group, 2007, Rothenberg, $1998 / 1999)$. One of the functions of clans is to provide protection to its members in exchange for obligations and loyalty (Landinfo, 2008). Clans also contribute to the administration of justice. Along with the official court system, there is a traditional conflict resolution system based on a mediation committee whose members are chosen by clans. This system is more likely to be involved in cases of conflict where members of different clans are involved.

Empirical evidence indicates significant and positive correlations between trust in clan and trust in public and international institutions. These positive correlations recall the role of community governance discussed by Bowles and Gintis (2002). They indicate with the term 'community governance' a social organism or group able to provide a set of norms and rules facilitating the interaction of the members in a more cooperative manner (Bowels and Gintis, 2002). One of the strengths of community governance is the access to private information not always available to public institutions. In this sense the community has greater access to the monitoring of the behaviour of its members and it also has the capability to punish individuals who behave against the established social norms. On the basis of their experimental findings, Bowles and Gintis (2002) stress the fact that community governance cannot represent a substitute institutional framework of the State but a complementary organism that may contribute to governance where the public institutions fail due to lack of information. This complementary synergy between community (clans) and

8 We thank an anonymous reviewer for suggesting this interpretation. 
public institutions is a crucial coping strategy for the institutional uncertainty represented by the Palestinian environment.

\section{Limitations of the study}

There are several reasons to treat these findings with caution. First, our indicator of prosocial attitudes is a latent variable obtained as a combination of a number of subjective measures that could have been unreliably reported by interviewees. Measures of trust are also given by subjective evaluations and thus exposed to common bias.

The cross-sectional design of the study is another limitation which requires caution in advancing a causal interpretation of the estimates. More generally, the nature of the phenomena under discussion exposes the analysis to endogeneity problems in two ways.

Firstly, institutional and knowledge-based trusts are subjective and cognitive phenomena, which depend on individual, specific and unobservable preferences and perceptions. Hence, they are by definition endogenously determined. Unobservable, individual characteristics such as personal interests and values or unexpected shocks may be correlated with both prosocial attitudes and trust. Secondly, the possibility of a reverse causality should not be overlooked, in that individuals who have a preference for prosocial behaviour may be more willing to trust institutions. The evolution of public institutions is the outcome of centuries of conflict between different formal and informal organizations, and within these organizations. Organizations must, in turn, be regarded as a form of institutions, as they involve systems of embedded rules, structures and networks (Hodgson, 2006). The extent to which public institutions are trustworthy (or are perceived as trustworthy) also is the result of the action of organizations and of individual actors within organizations. This suggests that individuals with a preference for prosocial behaviour may not simply be willing to trust institutions but also to mobilize to create trustworthy institutions. ${ }^{9}$

Our attempt to cope with endogeneity problems relies fundamentally on the use of SEM. Goldberger defines an SEM as 'A stochastic model where each equation represents a causal linkage, rather than a simple empirical association' (979). SEMs are composed of regression equations, which are included in the model only so far as it is possible to interpret them as causal relationships, theoretically justifiable and not falsified by data. However, it must be noted that, as other unexamined models may fit the data, if not better, an accepted model should be considered only as a 'not-disconfirmed' model. Thus, even if the use of SEM allows us to more reliably evaluate the relationship between trust and prosocial behaviour, the problem of causality still remains open to question, and causal ambiguities remain unsolved.

9 We are grateful to an anonymous reviewer for raising this point. 
In addition, our dataset does not allow us to control for relevant economic aspects such as income and wealth.

A more reliable investigation into the determinants of prosocial behaviour in the Territories requires the collection of a more comprehensive and longitudinal dataset, observing the evolution of trust and prosocial behaviour over a prolonged period of time.

\section{Conclusions}

Despite the weaknesses outlined above, our paper adds to the literature by using a unique dataset to provide the first empirical investigation into the determinants of prosocial behaviour in a specific yet extremely interesting case such as the Palestinian Territories. Based on an SEM analysis articulated in two steps - a measurement model and a pathway model - our results support the hypothesis that diverse types of trust may exert a different influence on prosocial behaviour depending on the institutional context and on the characteristics of the social fabric. Trust in public institutions is found to be significantly and positively correlated with prosocial behaviour, and its role seems to be markedly greater than that of knowledge-based trust, which is of only minor significance. Prosociality does not show any statistically significant relationship with trust in international organizations, despite their prominent role in the Territories' economy. At this stage of the Palestinian process of state capacity building, domestic institutions apparently play a greater role than international organizations in fostering the diffusion of cooperative behaviours.

We propose two explanations of these results. First, people who trust public institutions may be more confident that others will behave cooperatively, because they believe in the institutions' ability to enforce rules and to identify and punish cheaters. On the other hand, citizens who perceive public institutions as efficient and fair may feel the moral obligation to behave prosocially as part of a 'psychological contract' which ties them to the state.

This mechanism might provide additional speculative insights about the relationship between institutional quality and economic growth in the Territories. In this regard, Schein (2012) investigates the role of the quality of institutions in Palestine's economic prosperity between 1516 and 1948. This study suggests that Palestine experienced higher levels of economic growth in a period characterized by a tighter protection of private property and when the level of expropriation from the elite was low compare to periods of extractive institutions, lack of law and order, insecure property rights, entry barriers and other exogenous rigidities preventing the well-functioning of markets. Schein (2012) shows that during periods of institutional transparency and accountability, Palestinian Territories experienced not only reduced tax evasion and tax avoidance but also economic prosperity. On the basis of our findings, we might argue that higher institutional transparency and accountability increase 
institutional trust facilitating Palestinians cooperative behaviour and, hence, stimulating the local economy towards prosperity rather than stagnation.

The significant and positive correlation of trust in clans with both prosocial attitudes and institutional trust also suggest important implications for policy makers and researchers in two interconnected points of reflection. Firstly, for modernizing the Palestinian society, in addition to the strengthening of public institutions, and the cooperation with international organizations (whether UNconnected or not), the role of the local community needs to be considered. This might lead to the second point of reflection: a process of state capacity building needs the support of the local community, especially where community institutions are perceived as trustworthy and hold the power to enforce law across their members. Public institutions that recognize this role are more likely to gain the trust of their citizens and this can consolidate even more the establishment of the psychological contract.

Our findings also suggest that, in collectivist societies with low levels of generalized trust, the lack of citizens' confidence in the fairness and efficiency of public institutions may compromise social order. On the other hand, the strengthening of institutional trust may reinforce prosocial behaviour in individualist societies, where a decline in generalized trust has been documented by empirical studies.

\section{References}

Antoci, F., F. Sabatini, and M. Sodini (2013), 'Economic Growth, Technological Progress and Social Capital: The Inverted U hypothesis', Metroeconomica, 64(3): 401-431.

Aselage, J. and R. Eisenberger (2003), 'Perceived Organizational Support and Psychological Contracts: A Theoretical Integration', Journal of Organizational Behavior, 24(5): 491509.

Atran, S. (1986), 'Hamula Organisation and Masha'a Tenure in Palestine', Man, New Series, 21(2): 271-295.

Berigan, N. and K. Irwin (2011), 'Culture, Cooperation and the General Welfare', Social Psychology Quarterly, 74(4): 341-360.

Bogaert, S., Boone, C. and C. Declerck (2008), 'Social value orientation and cooperation in social dilemmas: A review and conceptual model', British Journal of Social Psychology, 47(3): 453-480.

Bollen, K. (1989), Structural Equations with Latent Variables, New York: Wiley.

Bowles, S. and H. Gintis (2002), 'Social Capital and Community Governance', Economic Journal 112(483): 419-436.

Brehm, J. and W. Rahn (1997), 'Individual Level Evidence for the Causes and Consequences of Social Capital', American Journal of Political Science, 41(3): 999-1023.

Buda, R. and S. M. Elsayed-Elkhouly (1998), 'Cultural Differences between Arabs and Americans: Individualism-Collectivism Revisited', Journal of Cross Cultural Psychology, 29(3): 487-492.

Bühlmann, M. and Freitag, M. (2009), 'Crafting Trust The Role of Political Institutions in a Comparative Perspective’, Comparative Political Studies, 42(12): 1537-1566. 
Christoforou, A. (2010), 'Social Capital and Human Development: An Empirical Investigation Across European Countries', Journal of Institutional Economics, 6(2): 191-214.

Crisis Group (2007), 'Inside Gaza: The Challenge of Clan and Families', Middle East Report N. 71, 20 December 2007.

Dasgupta, P. (2005), 'Economics of Social Capital', The Economic Record, 81(255): S2-S21.

Degli Antoni, G. (2009), 'Intrinsic versus Extrinsic Motivations to Volunteer and Social Capital Formation', Kyklos, 62(3): 359-370.

European Commission (2004), Palestinian Authority of the West Bank and Gaza Strip, European Neighbourhood Policy Country Report.

European Commission (2011), 'Implementation of the European Neighbourhood Policy in 2010 Country Report: Occupied Palestinian Territory. Joint Staff Working Paper COM (2011) 303.

Feld, L. P. and B. S. Frey (2002), 'Trust Breeds Trust: How Taxpayers are Ttreated', Economics of Governance, 3(2): 87-99.

Field, J. (2004), Social Capital, London and New York: Routledge.

Frey, B. S. and B. Torgler (2007), 'Tax Morale and Conditional Cooperation,' Journal of Comparative Economics, 35(1): 136-159.

Hodgson, G. M. (2006), 'What are institutions?', Journal of Economic Issues, 40(1): 1-25.

Hofstede, G. (1991), Cultures and Organizations: Software of the Mind, London: McGrawHill UK.

Irwin, K. (2009), 'Prosocial behavior across cultures: The effects of institutional versus generalized trust', In Shane R. Thye, Edward J. Lawler (ed.) Altruism and Prosocial Behavior in Groups (Advances in Group Processes, Volume 26), Emerald Group Publishing Limited, pp.165-198.

Kline, R. B. (2005), Principles and Practice of Structural Equation Modeling, New York: Guilford Press.

Knack, S. (2002), 'Trust, Associational Life and Economic Performance', The Contribution of Human and Social Capital to Sustained Economic Growth and Well-Being: International Symposium Report.

Knack, S. and P. Keefer (1997), 'Does Social Capital Have an Economic Payoff?', The Quarterly Journal of Economics, 112(4): 1251-1288.

Kumlin, S. and B. Rothstein (2005), 'Making and Breaking Social Capital', The Impact of Welfare-State Institutions,' Comparative Political Studies, 38(4): 339-365.

Kupek, E. (2006), 'Beyond Logistic Regression: Structural Equations Modelling for Binary Variables and its Application to Investigating Unobserved Confounders', BMC Medical Research Methodology, 6:13.

Landinfo (2008), Clan Conflicts in the Palestinian Territory, Oslo: Landinfo - Country of Origin Information Centre.

Lasensky, S. (2004), 'Paying for Peace. The Oslo Process and the Limits of American Foreign Aids,' Middle East Journal, 58(2): 210-234

Letki, N. (2006), 'Investigating the Roots of Civic Morality: Trust, Social Capital and Institutional Performance', Political Behavior, 28(4), 305-325.

Martínez-Vázquez, J. and B. Torgler (2009), 'The Evolution of Tax Morale in Modern Spain', Journal of Economic Issues, 43(1): 1-28.

Nasr, M. and J. Hilal (2007), Measuring Social Capital in the Palestinian Territories, The Palestine Jerusalem: Economic Policy Research Institute.

North, D. (1990), Institutions, Institutional Change and Economic Performance, Cambridge: Cambridge University Press. 
Oishi, S., U. Schimmack, Ed. Diener, and E. M. Sub (1998), 'The Measurement of Values and Individualism-Collectivism', Personality and Social Psychology Bulletin, 24(11): 1177-2000.

Olsson, U. H., T. Foss, S. V. Troye, and R. D. Howell (2000), 'The Performance of ML, GLS, and WLS Estimation in Structural Equation Modeling Under conditions of Misspecification and Nonnormality', Structural Equation Modeling, 7(4): 557-595.

Putnam, R. D. (2000), Bowling Alone: The Collapse and Revival of American Community, New York: Simon \& Schuster.

Putnam, R. D., R. Leonardi, and R. Y. Nanetti (1993), Making Democracy Work, Princeton: Princeton University Press.

Ring, P. S. and A. H. van de Ven (1992), 'Structuring Cooperative Relationships between Organizations', Strategic Management Journal, 13(7): 483-498.

Robinson, S. L. and D. M. Rousseau (1994), 'Violating the Psychological Contract: Not the Exception but the Norm', Journal of Organizational Behavior, 15(3): 245-259.

Rothenberg, C. E. (1998/99), 'A Review of the Anthropological Literature in English on the Palestinian Hamula and the Status of Women', Journal of Arabic and Islamic Studies, 2(2): 24-48.

Rothstein, Bo (2001), 'Social Capital in the Social Democratic Welfare State,' Politics and Society, 29(2): 207-241.

Rousseau, D. M. (1989), 'Psychological and Implied Contracts in Organizations', The Employee Rights and Responsibilities Journal, 2(2): 121-139.

Rousseau, D. M. (1995), Managing Diversity for High Performance, New York: Business Week/Advance.

Sabatini, F. (2008), 'Social Capital and the Quality of Economic Development', Kyklos, 61(3): 466-499.

Sarracino, F. (2010), 'Social Capital and Subjective Well-being Trends: Comparing 11 Western European Countries', The Journal of Socio-Economics, 39(4): 482-517.

Schein, A. (2012), 'Institutional Reversals and Economic Growth: Palestine 1516-1948', The Journal of Institutional Economics, 8(1): 119-141.

Smith, A. (1759), Theory of Moral Sentiments, London: A. Millar.

Tempelaar, D. T., S. S. Van Der Loeff, and W. H. Giselaers (2007), 'A Structural Equation Model Analyzing the Relationship of Students' Attitude Toward Statistics, Prior Reasoning Abilities and Course Performance', Statistics Education Research Journal, 6(2): 78-102.

Torgler, B. (2005a), 'Tax Morale and Direct Democracy', European Journal of Political Economy, 21(2), 525-531.

Torgler, B. (2005b), 'Tax Morale in Latin America', Public Choice, 122(1/2): 133-157.

Torgler, B. and F. G. Schneider (2007), 'What Shapes Attitudes toward Paying Taxes? Evicende from Multicultural European Countries', Social Science Quarterly, 88(2): 443-470.

Triandis, H. C. (1995), Individualism and collectivism, San Francisco: Westview Press.

Uphoff, N. (1999), 'Understanding Social Capital: Learning from the Analysis and Experience of Participation', in: P. Dasgupta and I. Serageldin (eds.), Social Capital: A Multifaceted Perspective, Washington, DC: The World Bank.

Uslaner, E. M. (2002), The Moral Foundations of Trust, Cambridge: Cambridge University Press.

World Bank (2003), Twenty-Seven Months - Intifada, Closures and Palestinian Economic Crisis, Washington, DC: World Bank. 
Yamagishi, T. (1988), 'The Provision of a Sanctioning System in the United States and Japan, Social Psychology Quarterly, 51(3): 265-271.

Yamagishi, T. and M. Yamagishi (1994), 'Trust and Commitment in the United States and Japan', Motivation and Emotion, 18(2): 129-166.

Yamamura, E. (2011), 'The Role of Social Trust in Reducing Long-Term Truancy and Forming Human Capital in Japan', Economics of Education Review, 30(2): 380-389.

Zak, P. J. and S. Knack (2001), 'Trust and Growth', Economic Journal, 111(470): 295-321. Zucker, L. G. (1986), 'Production of Trust: Institutional Sources of Economic Structure, 1840-1920', Research in Organizational Behavior, 8: 53-111.

\section{Appendix}

Table A1. Correlation matrix of behavioural items

\begin{tabular}{llllll}
\hline \hline & Work & Bribe & Abstention & Traffic & Stolen \\
\hline Work & 1.000 & & & & \\
Bribe & 0.235 & 1.000 & & & \\
Abstention & 0.234 & 0.134 & 1.000 & 1.000 & 1.000 \\
Traffic & 0.335 & 0.224 & 0.283 & 0.356 & \\
Stolen & 0.168 & 0.286 & 0.242 & & \\
\hline \hline
\end{tabular}

All the correlations have a $p$-value $<0.01$.

Table A2. Regression weights (measurement model prosocial behaviour)

\begin{tabular}{|c|c|c|c|c|c|c|c|}
\hline & & & Estimate & S.E. & C.R. & $\mathrm{P}$ & Label \\
\hline Stolen & $<-$ & Prosocial & 1.000 & & & & \\
\hline Traffic & $<-$ & Prosocial & 0.993 & 0.073 & 13.649 & $* * *$ & par_1 \\
\hline Abstention & $<-$ & Prosocial & 1.273 & 0.110 & 11.619 & $* * *$ & par_2 \\
\hline Bribe & $<-$ & Prosocial & 0.409 & 0.032 & 12.876 & $* * *$ & par_3 \\
\hline Work & $<-$ & Prosocial & 1.250 & 0.089 & 14.043 & $* * *$ & par_4 \\
\hline
\end{tabular}

*** $1 \%$ significance level.

Table A3. Squared multiple correlations

\begin{tabular}{ll}
\hline \hline & Estimate \\
\hline Work & 0.345 \\
Bribe & 0.111 \\
Abstention & 0.178 \\
Traffic & 0.290 \\
Stolen & 0.360 \\
\hline \hline
\end{tabular}

Table A4. Model fit indicators

\begin{tabular}{lllllll}
\hline \hline Indicator & CIMN/DF & RMSEA & GFI & AGFI & NFI & CFI \\
\hline Level in this analysis & 3.67 & 0.038 & 0.997 & 0.988 & 0.969 & 0.977 \\
Minimum Threshold level & $5<$ & $0.08<$ & 0.9 & 0.9 & 0.9 & 0.9 \\
\hline \hline
\end{tabular}


Table A5. Correlation matrix of the trust items in public institutions

\begin{tabular}{|c|c|c|c|c|c|c|c|}
\hline & $\begin{array}{l}\text { Trust } \\
\text { gov }\end{array}$ & $\begin{array}{l}\text { Trust } \\
\text { parties }\end{array}$ & $\begin{array}{l}\text { Trust } \\
\text { localgov }\end{array}$ & $\begin{array}{l}\text { Trust } \\
\text { parliam }\end{array}$ & $\begin{array}{l}\text { Trust } \\
\text { president }\end{array}$ & $\begin{array}{l}\text { Trust } \\
\text { judicial }\end{array}$ & $\begin{array}{l}\text { Trust } \\
\text { police }\end{array}$ \\
\hline Trust gov & 1.000 & & & & & & \\
\hline Trust parties & 0.552 & 1.000 & & & & & \\
\hline Trust localgov & 0.403 & 0.427 & 1.000 & & & & \\
\hline Trust parliam & 0.669 & 0.504 & 0.495 & 1.000 & & & \\
\hline Trust president & 0.335 & 0.461 & 0.332 & 0.401 & 1.000 & & \\
\hline Trust judicial & 0.328 & 0.344 & 0.417 & 0.430 & 0.536 & 1.000 & \\
\hline Trust police & 0.314 & 0.398 & 0.344 & 0.352 & 0.522 & 0.501 & 1.000 \\
\hline
\end{tabular}

All the correlations have a $p$-value $<0.01$.

Table A6. Regression weights - trust in institutions

\begin{tabular}{|c|c|c|c|c|c|c|c|}
\hline & & & Estimate & S.E. & C.R. & $\mathrm{P}$ & Label \\
\hline Trust_judicial & $<-$ & Trust public_institutions & 1.286 & 0.087 & 14.699 & $* * *$ & par_1 \\
\hline Trust_president & $<-$ & Trust public_institutions & 1.431 & 0.094 & 15.166 & $* * *$ & par_2 \\
\hline Trust_parliament & $<-$ & Trust public_institutions & 0.982 & 0.064 & 15.404 & $* * *$ & par_3 \\
\hline Trust_localgov & $<-$ & Trust public_institutions & 1.000 & & & & \\
\hline Trust_parties & $<-$ & Trust public_institutions & 1.096 & 0.066 & 16.592 & $* * *$ & par_4 \\
\hline Trust_gov & $<-$ & Trust public_institutions & 0.858 & 0.064 & 13.426 & $* * *$ & par_5 \\
\hline Trust_police & $<-$ & Trust public_institutions & 1.202 & 0.082 & 14.578 & $* * *$ & par_6 \\
\hline Trust_donors & $<-$ & Trust international_institutions & 1.000 & & & & \\
\hline Tust_intorganization & $<-$ & Trust international_institutions & 0.989 & 0.033 & 29.633 & $* * *$ & par_7 \\
\hline Trust_un & $<-$ & Trust international_institutions & 0.969 & 0.033 & 28.973 & $* * *$ & par_8 \\
\hline
\end{tabular}

Table A7. Model fit indicators

\begin{tabular}{lllllll}
\hline \hline Indicator & CIMN/DF & RMSEA & GFI & AGFI & NFI & CFI \\
\hline Level in this analysis & 3.32 & 0.04 & 0.98 & 0.97 & 0.92 & 0.94 \\
Minimum Threshold level & $5<$ & $0.08<$ & 0.9 & 0.9 & 0.9 & 0.9 \\
\hline \hline
\end{tabular}

Table A8. Squared multiple correlations (trust in public and international institutions)

\begin{tabular}{ll}
\hline \hline & Estimate \\
\hline Trust_un & 0.669 \\
Trust_intorganization & 0.750 \\
Trust_donors & 0.674 \\
Trust_police & 0.457 \\
Trust_gov & 0.219 \\
Trust_parties & 0.414 \\
Trust_localgov & 0.352 \\
Trust_parliament & 0.291 \\
Trust_president & 0.589 \\
Trust_judicial & 0.510 \\
\hline \hline
\end{tabular}


Table A9. Standardized regression weights (measurement model of trust in public and international institutions)

\begin{tabular}{llll}
\hline \hline & & & \\
\hline Trust_judicial & $<-$ & Trust public_institutions & Estimate \\
Trust_president & $<-$ & Trust public_institutions & 0.714 \\
Trust_parliament & $<-$ & Trust public_institutions & 0.768 \\
Trust_localgov & $<-$ & Trust public_institutions & 0.539 \\
Trust_parties & $<-$ & Trust public_institutions & 0.593 \\
Trust_gov & $<-$ & Trust public_institutions & 0.643 \\
Trust_police & $<-$ & Trust public_institutions & 0.467 \\
Trust_donors & $<-$ & Trust international_institutions & 0.676 \\
Trust_intorganization & $<-$ & Trust international_institutions & 0.821 \\
Trust_un & $<-$ & Trust international_institutions & 0.866 \\
\hline \hline
\end{tabular}

